\title{
Big data approaches and outcome of information asymmetry: opportunities for future research
}

\author{
Milind A. Mandlik* \\ Graduate School of Management, \\ University of Auckland, \\ Auckland 1010, New Zealand \\ Email: m.mandlik@auckland.ac.nz \\ *Corresponding author
}

\section{Djavlonbek Kadirov}

The School of Marketing and International Business,

Victoria University of Wellington,

Wellington 6011, New Zealand

Email: djavlonbek.kadirov@vuw.ac.nz

\begin{abstract}
The purpose of this paper is to advocate reorientation of current managerial practices in the light of growing reliance on Big Data strategies by contemporary firms, to make them more consumer-centric in nature. Big data strategies by their very nature and modalities lead to heightened levels of information asymmetry which by default have the capacity to disempower the very user that contributes towards the data driven insights. The fundamental driver for writing this paper is not to criticise big data strategies per se, but to suggest; it is merely a tool which can be equally used for consumer entrapment, as well as consumer empowerment. This paper wishes to contribute to the intellectual debate among academics, policy maker, and practitioners alike; en-route for a type of big data-driven managerial orientation that balances the consumers' right to market-based transparency, and the enterprise's need for economic viability.
\end{abstract}

Keywords: big data marketing; information asymmetry; stakeholder management; consumer empowerment.

Reference to this paper should be made as follows: Mandlik, M.A. and Kadirov, D. (2018) 'Big data approaches and outcome of information asymmetry: opportunities for future research', Int. J. Business Continuity and Risk Management, Vol. 8, No. 4, pp.303-318.

Biographical notes: Milind A. Mandlik is a Teaching Fellow in Marketing at the Graduate School of Management, University of Auckland Business School. $\mathrm{He}$ has received his $\mathrm{PhD}$ in Marketing from the University of Waikato in New Zealand. He understands and explores human behaviour through physiological, sociological and psychological processes fascinated by the ever-changing intricacies of human behaviour and its influence on consumption choices.

Djavlonbek Kadirov is a Lecturer in Marketing at the Victoria University of Wellington, New Zealand. He received his $\mathrm{PhD}$ in Marketing from the University of Waikato in New Zealand and MSc in Marketing with distinction from the Salford University in UK. His research interests include marketing 
systems, marketing and society, sustainable marketing, and authentic brands. His research has appeared in journals such as the Journal of Macromarketing, Journal of Marketing Management, Journal of Business Research, and Consumption Markets and Culture.

This paper is a revised and expanded version of a paper entitled 'Big data revolution: witnessing a new era of consumer vulnerability' presented at Australia New Zealand Marketing Conference, Sydney, Australia, 5-7 December 2015.

\section{Introduction}

The precursor for writing this paper emerged from the contemporary business organisation's ever increasing reliance on 'big data' strategies for attaining economic viability. The primary concern is that data capturing practices are consequently leading to amplified levels of resource imbalance (information asymmetry) between firms and its wider customer groups, which have the potential to hamper the process of value co-creation (Ratner, 2004; Chen et al., 2012; LaValle et al., 2011; Ghazal et al., 2013; Hofacker et al., 2016; Woodruff and Flint, 2006). There is an emerging debate around how big data-driven firms are remarkably concerned with finding new opportunities, and efficiencies, to produce, seduce, and market increasing the number of goods and services to the wider society (Zuboff and Maxmin, 2004; Craig and Ludloff, 2011; Persily, 2017). Primarily driven by their abilities to harness consumption insights through web-enabled services, which are offered free of cost to an unsuspecting audience. It seems these services are not free after all, a sentiment echoed by Krotoski and Kendall (2010) quoting, "we are being watched and traded [...] in return for a free web our privacy has become a commodity." The move has raised questions with regards to the type of stakeholder engagement strategies adopted by these firms, and the firm's awareness around possible revolt by the markets (individuals and groups) as a result of these prevailing big data harnessing practices. In more recent times the media coverage around communications research firms like 'Cambridge analytica' ha even called the legitimacy of data utilisation into question. There have been calls for a policy framework to be put in place to protect harnessing and utilisation of big data, which could fundamentally threaten not just individual and communal freedom but the very framework democracy of a country (Persily, 2017).

Scholars argue the contemporary business practices primarily operate under the ideology of value exchange that is inherently rooted in extractive economic transactions (Zwick et al., 2008; Price and Arnould, 1999). They often lament how the emergence of big data has allowed enterprises to take their extractive ideology a step further, by harnessing capacities to capture, profile, and store data-drive insights around patterns of individual consumption norms, also known as dataveillance (Ashworth and Free, 2006; Boyd and Crawford, 2012; Cadwalladr, 2017). Incidentally, many scholars have also raised concerns around increasing invasion of privacy, and its implications for consumer vulnerability associated with increasing usage of big data strategies (Mayer-Schönberger and Cukier, 2013; Ohlhausen, 2014; Craig and Ludloff, 2011; Boyd and Crawford, 2012; Bollier and Firestone, 2010; Cadwalladr, 2017). To some, the concern runs even deeper, since such web-enabled data repositories are fast becoming a sought-after 'commodity' 
which are open for further exploitation, and sometimes for purposeful breaches, commonly known as hacking (Davis, 2012; Experian, 2015; Searls, 2012; Acquisti et al., 2006).

Very little is known about if market actors including consumers are truly aware of the extent of big data-driven firm's abilities to capture their most personal consumption insights. Under some circumstances, information gathering exercises turn into the repeated utilisation of data insights that go far deeper than superficial, simplistic analysis of past purchase behaviours (Mayer-Schönberger and Cukier, 2013). The purpose of this article is to outline future research agenda for exploring the usage of big data capturing strategies, and the resultant outcome of information asymmetry (between the firm and its customers), which may ultimately hinder the very process of value co-creation. Section 1 of this article offers a brief introduction to the topic. Section 2 outlines the background to the big data sciences. Section 3 then discusses the contemporary managerial approaches of big data capturing practices. Section 4 describes the consequences of big data capture and its outcomes for stakeholder management strategies. Section 5 offers insights into the potential outcomes of information asymmetry via ecosystems viewpoint. Sections 6 and 7 provide a broad-based discussion around the potential fallout from this ongoing information asymmetry, as well as suggest an agenda for further research.

\section{Big data sciences}

For the purpose of explaining what 'big data' is, the extant literature has a variety of definitions available from bio-sciences to physics, chemistry, and astronomy and within social sciences as well. Big data is defined as "large volumes of high velocity, complex, and variable data that require advanced techniques and technologies to enable the capture, storage, distribution, management and analysis of the information" [Raghupathi and Raghupathi, (2014), p.2]. In practical terms, big data simply means exceedingly large amounts of information, which needs to be stored and processed with the help of specialised algorithmic techniques, which is beyond the abilities of a simple computational devices such as personal computers. The origins of the term big data lie in the early days of 'human genome' decoding projects and various projects in astronomy (Collins et al., 2003; Feigelson and Babu, 2012). The real strength of big data lies in its potential to enable inferential data analysis, at speeds and accuracies which have not been witnessed before. Bollier and Firestone (2010, p.36) quote that the purpose of big data is "to identify patterns that create answers to questions you didn't even know to ask."

\subsection{Benefits of big data}

In spite of it's in situ concerns, over the years big data strategies have certainly helped improve services in certain sectors of the economy. Especially within the healthcare sector, big data has been increasingly used to reduce the soaring costs associated with providing medical services. It also helps with improving information transparency across multiple players within the healthcare industry, i.e., physicians, pharmacies, nursing fraternities and policymakers by giving them open access to digitised information across multiple services, thereby enhancing their decision-making abilities (Raghupathi and Raghupathi, 2014; Groves et al., 2013). Within the financial sector, big data certainly 
helps to prevent or at times reducing fraudulent financial transactions (e.g., credit-card fraud) and protecting vulnerable consumers from identity thefts (Barlow, 2013; Patidar and Sharma, 2011). There is also growing evidence that big data strategies are used to reduce service disruptions in the energy supply and internet service provisioning industries, with obvious benefits to consumers who are increasingly reliant on these services (Minelli et al., 2012).

\subsection{The coming of age of big data}

Firm's ability for building computerised databases of all kinds are not novel concepts per se, and their usage has been prevalent for decades (Brown and Coopers, 1999; Hughes, 2005). What is new in recent times is the growth of personal computational devices such as smartphones, tablets, and similar mobile devices that are constantly connected to the World Wide Web. These devices are not only constantly connected to the web; they are equally interconnected to each other, in the process generating copious amounts of digital user data, which is captured in real-time, and analysed in real-time to draw inferences from. This is a big shift beyond simply trying to extract past purchase habits of customers from an in-house marketing intelligence database. This is a new era which Bollier and Firestone (2010) call "a radically new kind of knowledge infrastructure." This is made possible with the advent of 'cluster computing' and now with 'cloud computing' (Buyya et al., 2009). The capacities of cloud computing are on the rise, and the number of enterprises offering these technologies has grown significantly in the past decade. It is fast becoming evident that these technologies will become commonplace in most industries in one form or another (Buyya et al., 2009; Marr, 2016). These technologies have unleashed capacities to store and analyse large datasets, over the web, at much lower levels of capital investments needed to set up the basic infrastructure resulting in rapid expansion of these technologies in a very short space of time (Bryant et al., 2008; Hashem et al., 2015).

\section{Managerial approaches to big data}

Contemporary practitioners strive for building a committed and on-going relationship with consumers, to achieve sustained levels of financial viability over time. A basic tenet of customer relationship management, outlined by the concept called 'customer lifetime value' (CLV) (Price and Arnould, 1999; Venkatesan and Kumar, 2004). Literature suggests a gradual shift appears to be taking place, one that redefines the ultimate role of a firm from simply being a producer and seller of goods/services, to the one wanting to tirelessly facilitate the ultimate outcome working hand-in-hand in resource integration, with the customers co-producing value (Oliver, 2006; Vargo, 2009; Woodruff and Flint, 2006). This re-orientation may appear humanistic and consumer-centric in nature, yet points to one key observation. At no point throughout the past century, have the firms ever given up on their quest for maximising economic output from resultant business activities (Varey, 2010). The big data focus is seemingly adding yet another tool to the managerial basket to sharpen its arsenal for extracting even more economic value, not just for now, but for years to come (Columbus, 2016). This certainly raises questions about the nature of the relationship shared by big data deploying firms and the groups of customers it serves. The balance of power in such relationships seems to be tilted towards 
the firms, primarily driven by their ability to readily access one of the key resource (e.g., behavioural insights) needed for producing and delivering value propositions. This then raises a question around who ultimately controls value co-creating interactions, and if the episodes could ever be truly called co-creative when clearly the firm controls much of the resources which enable the process of co-creation.

\subsection{Authoritative tenet}

Within big data deployment practices, data once collected is stored forever (owing to decreasing storage costs and increasing capacities), hence can be used, re-used, and cross-referenced with other data to harness new and otherwise unnoticed behavioural insights. Consumption and associated behavioural dimensions that were not possible or obvious in the past, start to emerge as the data starts to 'speak' (Mayer-Schönberger and Cukier, 2013). To some scholars, this is a concerning development since firms are now able to actively use these insights to further their economic agenda, at the cost of the increased invasion of customer privacy (Bollier and Firestone, 2010). This change in strategy echoes much discussion found in the literature during the late 1980s and early 1990s, about challenges of managing markets in the information age, i.e., knowledge-based economies (KBE) (Quinn, 1992). All of this is done on the back of firm's capacities to capture, store and utilise this data for more than what it was initially collected/intended for. This certainly raises a multitude of concerns with regards to its fair usage (Bollier and Firestone, 2010; Boyd and Crawford, 2012; Richards and King, 2014).

\subsection{Privacy paradox}

Another major concern is the prevalence and invasion of big data technology in all spheres of life, and its ability to monitor customer behaviours at an individual level. Towards the end of 20th century information technology firms started to install cookies (i.e., racking technologies) on computers instead of offering free or better service provisioning in the future (Ashworth and Free, 2006; Miyazaki, 2008). All of this was done under the legislative guidelines, wherein customers were informed of such data gathering processes and were notified of its potential usage (Ohlhausen, 2014). The current levels of technological invasion in daily lives have apparently changed the end-game. The advent of 'wearable technologies' has become increasingly intrusive in its functionality (e.g., iWatch, Fitbit). Wearable technology, not only works in tandem with other mobile devices which can monitor people's geo-location data but also monitors their bodily functions, such as caloric consumption and expenditure throughout the day (Miyazaki, 2008; Limpf and Voorveld, 2015). This inadvertently makes the individual wearing such technologies, visible in the virtual world, in the form of a digital body print. Hence the resulting data capture becomes a virtual collection of data points to be stored, and used for future tracking, and sharing between entities (businesses) (Grossman and Vella, 2014; Krotoski and Kendall, 2010). This type of data dataveillance has long-term implications.

Case in point, firms that own micro information could share them with other service providers, such as health/life insurance service providers. In return, policy underwriters could suggest an individual client be charged higher or lower premiums, depending on 
how conscientious they were about their past health behaviour. This sounds like a scenario described by Mayer-Schönberger and Cukier (2013) called 'the dictatorship of data' which can paralyse privacy and heighten individual vulnerability. The level of invasion of privacy is most certainly unheard of and is very alarming. The dictatorship of data goes a step further and has the potential to be used for assigning and calculating potential risk scores to the firm's customer base on the basis of race, gender, and even ethnicity. When such profiling gets used for designing service offerings, fundamentally based on socio-culturally based risk markers of the customers, then it starts to breach the boundaries of fairness and equality. These types of discriminatory profiling of future customers are in fact contrary to the basic ideologies promoted by information technology firms, with was meant to be empowering and democratic in their ethos (Groshek, 2009). Ideologically it is contrary to how information technology providers were perceived to be, the great equaliser of 21 st century (especially by customers) captured in a quote by Murphy (2000, p.1), "we're witnessing the greatest transition of power in history, one that will take power away from the mightiest corporations and social institutions and give it to $[\ldots]$ consumers."

\subsection{The era of machine learning}

When a firm can capture deep-rooted insights into the daily consumption behaviours of each of its customers in real-time, it can then design and deliver specific products or services tailor-made for each user (Columbus, 2016; Barlow, 2013). On face value, this might seem like simple product/service customisation, but it goes further than that when it starts to precisely predict the next behavioural/consumption intent of each user. The real issue is that firms would claim that they are merely furthering consumer interests, although the real paradox is that firms have the ultimate capacity to determine what 'consumer benefits' should be. This is seen as a step too far into the realm of dataveillance, all for promoting the firm's economic agenda. It has the potential to cause economic as well as psychological harm by undermining the overall well-being of an individual or groups of consumers (Rezabakhsh et al., 2006). A perfect example to demonstrate the firm's capacity to control service offerings would be the dynamic pricing strategy often used by the airline industry to change ticket prices in real-time, based on information seeking habits of the regular customer.

Purchasing airline tickets while being monitored by dynamic pricing technologies the consumers could end up paying more than they needed to for the same airline, flying the same route, on the same day (Etzioni et al., 2003). These decisions are primarily based on the level of information asymmetry which exists between the firm and its clients. The firm is able to autonomously dictate and control when, and how much to charge each user, for each transaction, and that too in real-time. This certainly puts the enterprise in control on many fronts, which helps with its underlying agenda of maximising economic gains at the expense of consumer value. The entire set up then starts to play out as monopolistic competition, rather than the utopian desire of perfect competition, in the era of the digital economy, as envisaged by some scholars at the beginning of the 21 st century (Litan and Rivlin, 2001; Lal and Sarvary, 1999). This concerning sentiment is well captured by Rezabakhsh et al. (2006, p.9) when they quote, "[in a] restricted marketplace transparency; the firms can benefit [...] by imposing their economic interests at the expense of diverging consumer interests." 
The ongoing discussion raises some key questions with regards to big data-driven managerial practices and its implication for consumer vulnerability. At this juncture, we would like to highlight a few testable propositions which need to be explored further.

- Who ultimately controls the balance of power when firms interact with their consumers through web-enabled service provisioning?

- How do we make sure that the data harnessed once is used in a free and fair manner without disadvantaging the very consumer who parted with their intellectual capital?

- How do firms make sure that market-based transparency is maintained while the firms and its customers interact, and if not maintained what impact does it have on the consumers?

\section{Big data and stakeholder engagements}

Over the years information and communication technology services (ICTS) has facilitated the consumer's ever-increasing need for self-determination, which has a way of exhibiting itself in a variety of identities such as consumers, rebels, activists and that of citizens (Gabriel and Lang, 2006). All of these identities were motivated by a common theme of creatively resisting the template identities propagated by large enterprises (Üstüner and Holt, 2010). Consumer communities that play these roles found it empowering, as these identities shifted the locus of control in their favour away from the firms. The early literature on the impact of information technology-based service provisioning on marketing practice also hints to the fact that internet by its virtue transformed the traditional marketing practice into more of a democratic one (Pires et al., 2006). These services enabled consumers to access proprietary information like never before, made it easy for groups of consumers to band together, resulting in a collective voice, and take an active role in the value chain, something that was not possible in the traditional systems (Rezabakhsh et al., 2006; Umit Kucuk and Krishnamurthy, 2007). Literature has documented the rise of the 'prosumers' or 'producers', driven by need for taking control away from large firms, and practice consumption without the fear of exploitation (Kotler and Levy, 1969; Grinnell, 2009; Ritzer et al., 2012; Arvidsson, 2011; Toffler, 2006). Suggestions were made that large firms needed to note this change in consumer intention, and learn to play the role of a symbiotic partner; in the process moving away from the traditional approaches of economic value extraction (Pitt et al., 2002). Firms needed to co-create the best possible outcome for the good of the entire ecosystem.

The classical stakeholder theory suggests the consumers (individuals or groups) are part of the wider network of actors the firm does business with (Bhattacharya and Korschun, 2008). Hence they are to be treated as one of the key stakeholders in the firm-consumer relationships. Recent conceptualisations through the lenses of 'service ecosystems' view have taken the argument a step further suggesting one needs to consider the customer (social actor) as a primary stakeholder in the firm-consumer relationship (Frow et al., 2014). The service ecosystem view suggests the focal firm can only make value propositions (i.e., co-creating opportunities) to the social actors. Then through the process of knowledge sharing, and resource integration, would the customer willingly participate in those value co-creative opportunities. Frow et al. (2014, p.331) 
point out "markets no longer simply deliver value, but become a place where dialogue among the consumer and the firm, consumer communities and networks of the firm can take place." This suggests for value co-creation to occur the environment needs to be conducive enough, and devoid of any hindrance such as lack of information (i.e., asymmetry), availability of opportunities for knowledge sharing, as well as sharing of resources. Based on the discussion in the previous section it is evident that big data strategies have tilted the information balance in favour of the firms. This is concerning since increasing information asymmetry ultimately has the potential to undermine genuine stakeholder relationship building processes that occur between the firm and its consumers.

The issue of information asymmetry may have a far-reaching consequence for the entire network of firms involved during the episodes of (firm-customer) value co-creation. It is proposed that in the value co-creative processes, firm and its customers act as collaborators and competitors at the same time (Ballantyne and Varey, 2006; Kowalkowski, 2011). The key role of the customer is to find and work with a firm that offers the best value propositions through the process of "planning, searching, selecting, negotiating and evaluating a range of value propositions [...] (through theses) experiences, actors are engaged, informed, connected and empowered" [Frow et al., (2014), p.332]. If all of this were to happen each time the firms-customers interact, then the customer is to be given unobtrusive access to information sources through which appropriate knowledge sharing can occur, and genuine engagement choices could be made. Big data led information asymmetry certainly precludes the customers from accessing the data repository harnessed by the firms. All signs are pointing to a general lack of willingness demonstrated by firms to change the status quo, remedy the information asymmetry, and carry out genuine stakeholder engagements based on good faith.

The ongoing discussion raises some key questions with regards to big data-driven managerial practices and its implication for stakeholder engagement strategies. At this juncture, we would like to highlight a few testable propositions which need to be explored further.

- Does increasing information asymmetry gap between firms and their customers have a tangible impact on the relational outcomes for stakeholder engagement strategies?

- Could the increasing information asymmetry gap between the firms and its consumers ultimately impact upon the very processes of value co-creation over time?

\section{Service ecosystem and outcomes of information asymmetry}

Scholars have also argued that the firms could be held accountable only up to a point, beyond which the roles and responsibilities of the customers engaging with firms known for data capturing abilities are to be questioned (Aguirre et al., 2016; Smith et al., 2011). Digital behavioural insights at times are offered by 'willing participants' while using ICTS or are unwittingly captured by third-party service providers (e.g., credit cards, mobile apps). But the stakes are truly different in a web-enabled environment. Firms have started treating data capture as a strategic resource and as means to building sustainable competitive advantage (LaValle et al., 2011; Chen et al., 2012). The users of web-enabled services have in fact become the product in themselves, wherein they produce the 
resultant value for the firms, including for their fellow customers (Leadbeater, 2009). Research suggests big data-driven firms rarely offer anything for free unless they can harvest additional data insights with each interaction with the service user (Searls, 2012). There are inherent issues with the way the big data-driven business practice has evolved over the past decade, and maybe needs a closer look at the status quo.

From the 'service ecosystems' viewpoint, the entire system operates at three separate levels (see figure 1). The first (micro) level consists of the social actor him/herself including their (individual) pattern of consumption behaviours while using the services of firms that are known for their routine data capturing practices. The second (meso) level focuses on the firm-actor relationship wherein the social actor is considered one of the key stakeholders of that ongoing relationship and the data capture is shared by a network of firms with a promise of better service provisioning. The third (macro) and final level involve all of the other stakeholders included within the wider ecosystem, beyond the firm-actor relationship. It involves every member of the community and the society at large.

Figure 1 Service ecosystem and stakeholder engagements (see online version for colours)

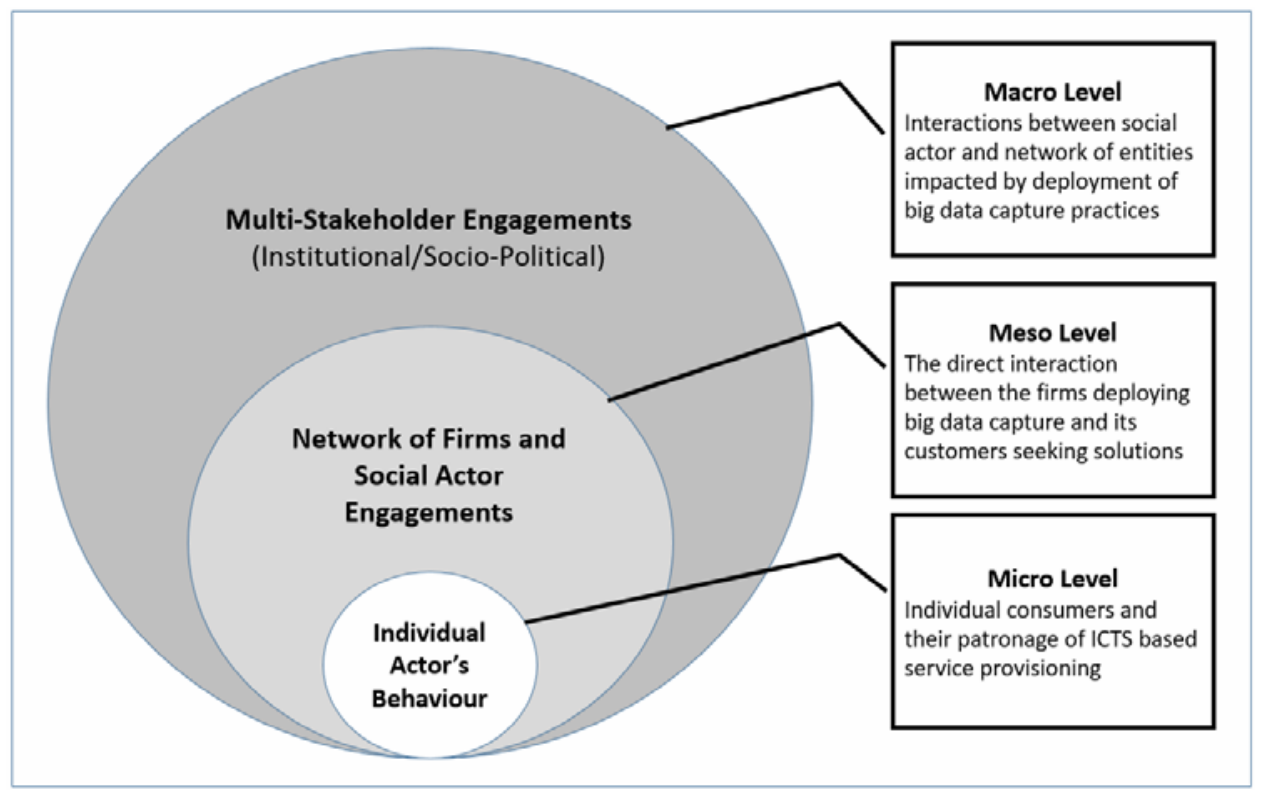

\subsection{Personal norms and behaviours (micro)}

Web-enabled services have become an essential part of most economies around the world, and our daily lives too. Looking at the current levels of utilisation of these services, one may argue they have become part of the ecological landscape of consumers' everyday lives. These consumers are increasingly reliant on a variety of web-enabled services, which have made their lives convenient, and a lot more efficient in all respects. It is fair to say, as the current systems were conceived, designed and deployed to fit around the lives of individual social actors (Tapscott, 1996). Looking at the rate at which a variety of web-enabled service has either been conceived or even deployed, it will be 
far too naïve to hope that individual consumer will take complete responsibility for these system's outcomes. Humans by nature are communal creatures, and all forms of communication have always been a major part of how the society interacts, comprehends life, and stays connected as a community (Bandura, 1986, 2001). Web-enabled services such as social media platforms and search engines have made it easier to enhance that connectivity between people around the globe, and also help individuals stay informed as citizens or even as consumers. These services have also become very pervasive, wherein individual consent for data capture has taken a back seat. This may be in part due to the information asymmetry which exists between the web-enabled service providers, and an average consumer who is simply trying to fulfil their needs of social cohesion (Chiu et al., 2006; Hollenbaugh and Ferris, 2014).

The level of information asymmetry that exists between an average user of web-enabled services, and the firms providing such services is often completely out of balance. Big data-driven firms capture and process copious amounts of data each day, increasingly supported by predictive algorithms. The ability to data-mine and explore deep-seated insights with the help of algorithms is limitless. Hence the information asymmetry will possibly be tilted in favour of the firms using such technologies. It is evident that these firms will need to take the lead, and make all of its data capturing and mining processes as transparent as possible, coupled with educating the individual consumers upfront of its full intentions of data capture and analysis as clearly as possible. From the service ecosystems viewpoint "the focus of a business strategy (must be) balance(ing) the value co-created and extracted from each group (members of society) so that overall benefits can be sustained [...] the well-being of the ecosystem depends on value propositions that support (genuine stakeholder) relationships" [Frow et al., (2014), p.335].

\subsection{Institutional norms and behaviours (meso)}

Web-enabled service providers have evolved as one of the major players in the world economies, worth millions of dollars in annual revenue. In their quest to legally protect themselves, and also each consumer who sign up for their services, everyone is duly asked to give consent. Every firm puts out a privacy policy for users to read, but these policy documents are mostly written in a language(s) which is laden with legislative jargon, generally beyond the comprehension abilities of a layperson. When consumers sign up to such policies, they are in effect consenting to capture of behavioural data. Later these behavioural insights are shared with a network of firms, even the firm harnessing such data insights are largely unaware of the possible secondary or tertiary usage of the data they collect. These firms do not know what they might discover in the data once collected, how that might spur novel product/service idea for future deployment. This very nature of secondary and tertiary analysis makes it harder for focal firms to ask consumers to consent to possible utilisation of their behavioural insights. Since these firms themselves do not know if, when and how these data-led insights could be utilised in the future. This makes the job of the focal firm genuinely difficult, knowing full well that they have to comply with the most recent policy framework designed to protect consumer groups. 


\subsection{Collective norms and behaviours (macro)}

Over the years, governmental bodies like consumer affairs, commerce commission and competition and consumer commission, have been on the forefront of advocating and protecting the rights of consumers and making sure any breaches of privacy are put on notice. With the big data revolution, the complexity around privacy policy has increased manifold and is becoming much more difficult to monitor every breach, especially in the web-based environment. On a practical level, the legislators have to strike a balance between protecting individual rights to privacy, while advocating for economic prosperity brought about by web-based service provisioning in the forms of employment and income taxes. This is a balancing act to achieve between advocating for consumer protection and the need for job creation.

The ongoing discussion raises some key questions with regards to big data-driven managerial practices and its implication for the health of the service ecosystem itself. At this juncture, we would like to highlight a few testable propositions which need to be explored further.

- What strategies could the firms adopt to remedy the ever-increasing information asymmetry between them and their key stakeholders, i.e., the consumers?

- What role do the firms have to play to make sure not just the focal firm but the entire network of firms it collaborates with is equally transparent when interacting with the wider service ecosystem?

\section{Discussion}

Evidently, since the 1980s consumers have learned their way around the internet democracy while enjoying this new found power and freedom. In its early days the internet was seen as the great enabler, that offered the consumers a level playing field when dealing with firms, quoted by Rezabakhsh et al. $(2006$, p.13) "the thesis that the internet enhances consumer power is primarily based on the assumption that diffusion of the internet helps to reduce information asymmetries and to improve market transparency for consumer." Similarly, firms were not certain as to how best to 'capitalise' on this emerging information-led industrial revolution (Krotoski and Kendall, 2010). The true nature of this power-shift became evident towards the end of the first decade of the 21st century when firms realised the real power of big data strategies (Mayer-Schönberger and Cukier, 2013). Consumers in their quest for staying informed as well as connected increasingly started using search engines, electronic mail services, and social media sites worldwide. Eventually, with the advent of smartphones, all of these behaviours were transferred over to mobile devices. In the process, this change in behaviour created a huge digital footprint for enterprises to capture, store and subsequently analyse for purposes of designing new business ideas. On the one hand, it seemed that the consumers were in control, but their online behaviours shifted the power back into the hands of firms who were able to harness behavioural insights in real-time and share it with network firms.

The real issue is the gap between what is private and what is public, least in the web-based environment has started to get blurry. This by default raises a lot of red flags 
around how much does the average consumer know, or perhaps understands that their web-based behaviours can put their 'off-line' behaviours at risk. The levels of information asymmetry between the firm and its consumers are at a concerning stage and set to grow at an exponential rate unless corrective actions are taken. Contrary to the earlier comment by Murphy (2000), in this web-enabled service provisioning era, the consumer is increasingly looking like a disempowered or vulnerable entity. It seemingly shows all the shades of vulnerability, as defined by Smith and Cooper-Martin (1997, p.4) "those who are more susceptible to economic, physical, or psychological harm in, or as a result of, economic transactions because of characteristics that limit their ability to maximise their utility and well-being."

\section{Research agenda}

Evidently, the current levels of consumer entrapment arising out of big data modalities operationalised by firms is a complex issue. Yet it has the potential to offer a level playing field to consumers who wish to be empowered. It is certainly in the interest of the firms to be as forthcoming and transparent as possible, with their motivations and abilities to capture and to analyse deep-rooted consumer insights, via the means of big data strategies. Web-enabled services and the concerns around consumer privacy is a contemporary and fascinating topic, which offers ample opportunities for further research. The next table (Table 1) captures all of the research questions raised so far and we would encourage researchers to operationalise interpretive or quantitative research strategies deemed suitable to explore these questions further.

Table 1 Broader research agenda for future exploration

\begin{tabular}{ll}
\hline No. & \multicolumn{1}{c}{ Questions } \\
\hline 1 & $\begin{array}{l}\text { Who ultimately controls the balance of power when firms interact with their consumers } \\
\text { through web-enabled service provisioning? }\end{array}$ \\
2 & $\begin{array}{l}\text { How do we make sure that the data harnessed is used in a free and fair manner without } \\
\text { disadvantaging the very consumer who parted with their intellectual capital? }\end{array}$ \\
3 & $\begin{array}{l}\text { How do firms make sure that market-based transparency is maintained while the firms } \\
\text { and its customers interact, and if not maintained what impact does it have on the }\end{array}$ \\
consumers? & $\begin{array}{l}\text { Does increasing information asymmetry gap between firms and their customers have a } \\
\text { tangible impact on the relational outcomes for stakeholder engagement strategies? }\end{array}$ \\
5 & $\begin{array}{l}\text { Could the increasing information asymmetry gap between the firms and its consumers } \\
\text { ultimately impact upon the very processes of value cocreation over time? }\end{array}$ \\
6 & $\begin{array}{l}\text { What strategies could the firms adopt to remedy the ever-increasing information } \\
\text { asymmetry between them and their key stakeholders, i.e., the consumers? }\end{array}$ \\
7 & $\begin{array}{l}\text { What role do the firms have to play to make sure not just the focal firm but the entire } \\
\text { network of firms it collaborates with is equally transparent when interacting with the } \\
\text { wider service ecosystem? }\end{array}$ \\
\hline
\end{tabular}

Albeit it is a complex and a multi-faceted research topic which can offer varied scope for researchers from different research traditions. Exploring the levels of information asymmetry between the firms and the individual users (consumers) is one such topic which needs further research. One more topic which offers research prospects would be, 
to understand the behaviours of consumer who have deliberately/consciously refrained from adopting to web-enabled service provisions. It will be equally interesting to understand the role of consumer education strategies and its role in empowering the consumer groups engaging with various web-enabled services.

\section{References}

Acquisti, A., Friedman, A. and Telang, R. (2006) 'Is there a cost to privacy breaches? An event study', ICIS 2006 Proceedings, p.94.

Aguirre, E., Roggeveen, A.L., Grewal, D. and Wetzels, M. (2016) 'The personalization-privacy paradox: implications for new media', Journal of Consumer Marketing, Vol. 33, No. 2, pp.98-110.

Arvidsson, A. (2011) 'Ethics and value in customer co-production', Marketing Theory, Vol. 11, No. 3, pp.261-278.

Ashworth, L. and Free, C. (2006) 'Marketing dataveillance and digital privacy: using theories of justice to understand consumers' online privacy concerns', Journal of Business Ethics, Vol. 67, No. 2, pp.107-123.

Ballantyne, D. and Varey, R. (2006) 'Introducing a dialogical orientation to the service-dominant logic of marketing', in Robert Lusch, S.V. (Ed.): The Service Dominant Logic of Marketing, M.E. Sharpe, New York.

Bandura, A. (1986) Social Foundations for Thought and Action: a Social Cognitive Theory, NJ Prentice-Hall, Englewood.

Bandura, A. (2001) 'Social cognitive theory: an agentic perspective', Annu. Rev. Psychol., Vol. 52, No. 1, pp.1-26.

Barlow, M. (2013) Real-Time Big Data Analytics: Emerging Architecture, O'Reilly Media, Inc, California.

Bhattacharya, C.B. and Korschun, D. (2008) 'Stakeholder marketing: beyond the four Ps and the customer', Journal of Public Policy \& Marketing, Vol. 27, No. 1, pp.113-116.

Bollier, D. and Firestone, C.M. (2010) The Promise and Peril of Big Data, Aspen Institute, Communications and Society Program, Washington, DC.

Boyd, D. and Crawford, K. (2012) 'Critical questions for big data: Provocations for a cultural, technological, and scholarly phenomenon', Information, Communication \& Society, Vol. 15, pp.662-679.

Brown, S.A. and Coopers, P.W. (1999) Customer Relationship Management: a Strategic Imperative in the World of E-Business, John Wiley and Sons, Inc, New York.

Bryant, R., Katz, R.H. and Lazowska, E.D. (2008) Big-Data Computing: Creating Revolutionary Breakthroughs in Commerce, Science and Society [online] https://cra.org/ccc/initiatives.

Buyya, R., Yeo, C.S., Venugopal, S., Broberg, J. and Brandic, I. (2009) 'Cloud computing and emerging IT platforms: vision, hype, and reality for delivering computing as the 5th utility', Future Generation Computer Systems, Vol. 25, No. 6, pp.599-616.

Cadwalladr, C. (2017) The Great British Brexit Robbery: How our Democracy was Hijacked [online] https://www.theguardian.com/technology/2017/may/07/the-great-britishbrexit-robbery-hijacked-democracy.

Chen, H., Chiang, R.H. and Storey, V.C. (2012) 'Business intelligence and analytics: from big data to big impact', MIS Quarterly, Vol. 36, No. 4, pp.1165-1188.

Chiu, C-M., Hsu, M-H. and Wang, E.T. (2006) 'Understanding knowledge sharing in virtual communities: an integration of social capital and social cognitive theories', Decision Support Systems, Vol. 42, No. 3, pp.1872-1888.

Collins, F.S., Morgan, M. and Patrinos, A. (2003) 'The human genome project: lessons from large-scale biology', Science, Vol. 300, No. 5617, pp.286-290. 
Columbus, L. (2016) Ten Ways Big Data Is Revolutionizing Marketing And Sales, Forbes Jersey City, New Jersey.

Craig, T. and Ludloff, M.E. (2011) Privacy and Big Data, O'Reilly Media, Inc, Sebastopol, California.

Davis, K. (2012) Ethics of Big Data: Balancing Risk and Innovation, O'Reilly Media, Inc, Sebastopol, California.

Etzioni, O., Tuchinda, R., Knoblock, C.A. and Yates, A. (2003) 'To buy or not to buy: mining airfare data to minimize ticket purchase price', Proceedings of the 9th ACM SIGKDD International Conference on Knowledge Discovery and Data Mining, ACM, pp.119-128.

Experian (2015) 2015 Data Breach Industry Forecast [online] http://www.experian.com/assets/ data-breach/white-papers/2015-industry-forecast-experian.pdf?_ga=1.172114915. 1943093614.1418003182.

Feigelson, E.D. and Babu, G.J. (2012) 'Big data in astronomy', Significance, Vol. 9, No. 4, pp.22-25.

Frow, P., Mccoll-Kennedy, J.R., Hilton, T., Davidson, A., Payne, A. and Brozovic, D. (2014) 'Value propositions: a service ecosystems perspective', Marketing Theory, Vol. 14, No. 3, pp.327-351.

Gabriel, Y. and Lang, T. (2006) The Unmanageable Consumer, Sage Publications Limited, California.

Ghazal, A., Rabl, T., Hu, M., Raab, F., Poess, M., Crolotte, A. and Jacobsen, H-A. (2013) 'BigBench: towards an industry standard benchmark for big data analytics', Proceedings of the 2013 ACM SIGMOD International Conference on Management of Data, ACM, pp.1197-1208.

Grinnell, C.K. (2009) 'From consumer to prosumer to produser: who keeps shifting my paradigm? (We do!)', Public Culture, Vol. 21, No. 3, pp.577-598.

Groshek, J. (2009) 'The democratic effects of the internet, 1994-2003 a cross-national inquiry of 152 countries', International Communication Gazette, Vol. 71, pp.115-136.

Grossman, L. and Vella, M. (2014) Never Offline : iNeed TIME, Singapore TIME South Pacific.

Groves, P., Kayyali, B., Knott, D. and Van Kuiken, S. (2013) The 'big data' revolution in healthcare', McKinsey Quarterly, Vol. 4, No. 1, pp.24-35

Hashem, I.A.T., Yaqoob, I., Anuar, N.B., Mokhtar, S., Gani, A. and Khan, S.U. (2015) 'The rise of 'big data' on cloud computing: review and open research issues', Information Systems, Vol. 47, pp.98-115.

Hofacker, C.F., Malthouse, E.C. and Sultan, F. (2016) 'Big data and consumer behavior: imminent opportunities', Journal of Consumer Marketing, Vol. 33, No. 2, pp.89-97.

Hollenbaugh, E.E. and Ferris, A.L. (2014) 'Facebook self-disclosure: examining the role of traits, social cohesion, and motives', Computers in Human Behavior, January, Vol. 30, pp.50-58.

Hughes, A.M. (2005) Strategic Database Marketing, McGraw-Hill Pub., Co, New York.

Kotler, P. and Levy, S. (1969) 'Broadening the concept of marketing', Journal of Marketing, Vol. 33, No. 1, pp.10-15.

Kowalkowski, C. (2011) 'Dynamics of value propositions: insights from service-dominant logic', European Journal of Marketing, Vol. 45, Nos. 1/2, pp.277-294.

Krotoski, A. and Kendall, D. (2010) The Virtual Revolution: the Cost of Free, BBC, UK.

Lal, R. and Sarvary, M. (1999) 'When and how is the internet likely to decrease price competition?', Marketing Science, Vol. 18, No. 4, pp.485-503.

Lavalle, S., Lesser, E., Shockley, R., Hopkins, M.S. and Kruschwitz, N. (2011) 'Big data, analytics and the path from insights to value', MIT Sloan Management Review, Vol. 52, No. 2, p.21.

Leadbeater, C. (2009) We-Think, Profile Books, London. 
Limpf, N. and Voorveld, H.A. (2015) 'Mobile location-based advertising: how information privacy concerns influence consumers' attitude and acceptance', Journal of Interactive Advertising, Vol. 15, No. 2, pp.111-123.

Litan, R.E. and Rivlin, A.M. (2001) 'Projecting the economic impact of the internet', The American Economic Review, Vol. 91, No. 2, pp.313-317.

Marr, B. (2016) Surprisingly, these 10 Professional Jobs are Under Threat from Big Data, Forbes Jersey City, NJ.

Mayer-Schönberger, V. and Cukier, K. (2013) Big Data: a Revolution that will Transform how we Live, Work, and Think, Houghton Mifflin Harcourt, Boston.

Minelli, M., Chambers, M. and Dhiraj, A. (2012) Big Data, Big Analytics: Emerging Business Intelligence and Analytic Trends for Today's Businesses, John Wiley and Sons, New Jersey.

Miyazaki, A.D. (2008) 'Online privacy and the disclosure of cookie use: effects on consumer trust and anticipated patronage', Journal of Public Policy \& Marketing, Vol. 27, No. 1, pp.19-33.

Murphy, T. (2000) Web Rules: how the Internet is Changing the Way Consumers Make Choices, Dearborn Financial Publishing, Inc, Michigan.

Ohlhausen, M.K. (2014) 'Privacy challenges and opportunities: the role of the federal trade commission', Journal of Public Policy \& Marketing, Vol. 33, No. 1, pp.4-9.

Oliver, R. (2006) 'Co-producers and co-participants in the satisfaction process', in Robert Lusch, S.V. (Ed.): The Service Dominant Logic of Marketing, M.E. Sharpe, New York.

Patidar, R. and Sharma, L. (2011) 'Credit card fraud detection using neural network', International Journal of Soft Computing and Engineering (IJSCE), Vol. 1, pp.32-38.

Persily, N. (2017) 'Can democracy survive the internet?', Journal of Democracy, Vol. 28, No. 2, pp.63-76.

Pires, G.D., Stanton, J. and Rita, P. (2006) 'The internet, consumer empowerment and marketing strategies’, European Journal of Marketing, Vol. 40, Nos. 9/10, pp.936-949.

Pitt, L., Berthonb, P., Watson, R. and Zinkhan, G. (2002) 'The internet and the birth of real consumer power’, Business Horizons, Vol. 45, No. 4, pp.7-14.

Price, L. and Arnould, E. (1999) 'Commercial friendships: service provider-client relationships in context', Journal of Marketing, Vol. 63, No. 4, pp.38-56.

Quinn, J.B. (1992) 'The intelligent enterprise a new paradigm', Academy of Management Perspectives, Vol. 6, No. 2, pp.48-63.

Raghupathi, W. and Raghupathi, V. (2014) 'Big data analytics in healthcare: promise and potential', Health Information Science and Systems, Vol. 2, p.3.

Ratner, B. (2004) Statistical Modeling and Analysis for Database Marketing: Effective Techniques for Mining Big Data, CRC Press, Boca Raton, Florida.

Rezabakhsh, B., Bornemann, D., Hansen, U. and Schrader, U. (2006) 'Consumer power: a comparison of the old economy and the internet economy', Journal of Consumer Policy, Vol. 29, No. 1, pp.3-36.

Richards, N.M. and King, J.H. (2014) 'Three paradoxes of big data', Stanford Law Review Online, Vol. 66, No. 2, p.41.

Ritzer, G., Dean, P. and Jurgenson, N. (2012) 'The coming of age of the prosumer', American Behavioral Scientist, Vol. 56, No. 4, pp.379-398.

Searls, D. (2012) The Intention Economy: When Consumers Take Charge, Harvard Business Review Press, Boston, MA.

Smith, H.J., Dinev, T. and $\mathrm{Xu}, \mathrm{H}$. (2011) 'Information privacy research: an interdisciplinary review’, MIS Quarterly, Vol. 35, pp.989-1016.

Smith, N.C. and Cooper-Martin, E. (1997) 'Ethics and target marketing: the role of product harm and consumer vulnerability', The Journal of Marketing, Vol. 35, No. 4pp.1-20.

Tapscott, D. (1996) The Digital Economy: Promise and Peril in the Age of Networked Intelligence, McGraw-Hill, New York. 
Toffler, A. (2006) 'Revolutionary wealth', New Perspectives Quarterly, Vol. 23, No. 3, pp.7-15.

Umit Kucuk, S. and Krishnamurthy, S. (2007) 'An analysis of consumer power on the internet', Technovation, Vol. 27, No. 1, pp.47-56.

Üstüner, T. and Holt, D.B. (2010) 'Toward a theory of status consumption in less industrialized countries', Journal of Consumer Research, Vol. 37, No. 1, pp.37-56.

Varey, R. (2010) 'Marketing means and ends for a sustainable society: a welfare agenda for transformative change', Journal of Macromarketing, Vol. 30, No. 2, pp.112-126.

Vargo (2009) 'Toward a transcending conceptualization of relationship: a service-dominant logic perspective', Journal of Business and Industrial Marketing, Vol. 24, Nos. 5/6, pp.373-379.

Venkatesan, R. and Kumar, V. (2004) 'A customer life time value framework for customer selection and resource allocation strategy', Journal of Marketing, Vol. 68, pp.106-125.

Woodruff, R. and Flint, D. (2006) 'Marketing's services dominant logic and customer value', in Robert Lusch, S.V. (Ed.): The Service-Dominant Logic of Marketing, M.E. Sharpe, New York.

Zuboff, S. and Maxmin, J. (2004) The Support Economy: why Corporations are Failing Individuals and the Next Episode of Capitalism, Viking Books/Penguin Books, New York.

Zwick, D., Samuel, B. and Darmody, A. (2008) 'Putting consumers to work: 'co-creation' and the new marketing govern-mentality', Journal of Consumer Culture, Vol. 8, No. 2, pp.163-196. 